\title{
Entre Martelos e Lâminas: Dinâmicas Globais e Políticas de Produção na Indústria do Caju em Moçambique
}

Fernando Bessa Ribeiro

\section{INTRODUÇÃO}

$\mathrm{E}$ ntre maio de 2001 e janeiro de 2004, fiz trabalho de campo em Moçambique para minha tese de doutorado, que tratou das dinâmicas do capitalismo nesse país (Ribeiro, 2004). Estudei um modo concreto de integração de um país da África Austral no sistema global capitalista, tomando como objeto central a indústria do caju. Esse trabalho de compreensão das dinâmicas do capitalismo, algumas de amplitude secular e que se fazem sentir localmente, teve como lugar principal, mas não exclusivo, Manjacaze (província de Gaza) e suas duas fábricas de caju. Criadas em épocas históricas diferentes, não só refletem os modos de vida em Moçambique, desde meados da segunda metade do século XX, como também são alavancas para mudanças.

Os processos e os fenômenos sociais que envolvem os países periféricos - naquilo que muitos designam como desenvolvimento - são um terreno de investigação partilhado pela antropologia e pela sociologia. No entender de Olivier de Sardan (1995:5 e ss., tradução do autor), trata-se de um domínio em que essas disciplinas não podem ser colocadas em oposição nem distinguidas. Por isso, o autor opta pelo conceito amplo de "socioantropologia da mudança social e do desenvolvimento", procurando assim definir uma nova disciplina. Não podendo existir separada da sociologia e da antropologia em geral, está marcada pela

DADOS - Revista de Ciências Sociais, Rio de Janeiro, Vol.51, n-2, 2008, pp. 511 a 531. 
transversalidade disciplinar. Ligada aos processos de mudança social provocados pela industrialização na África (Bazin, 2001:112), essa socioantropologia é simultaneamente uma antropologia política, uma sociologia das organizações, uma antropologia econômica, uma sociologia das redes, uma antropologia das representações e dos sistemas de sentido. Olivier de Sardan (1995:10) define-a como o estudo empírico multidimensional de grupos sociais contemporâneos e de suas interações em uma perspectiva diacrônica, combinando a análise das práticas com a das representações. Isso implica uma análise intensiva e in situ das dinâmicas de reprodução e transformação de aspectos sociais de natureza diversa, levando-se em conta tanto os comportamentos de seus autores como os significados que eles atribuem a esses comportamentos $^{1}$.

Em face da problemática imaginada e do quadro teórico utilizado - ancorado nos trabalhos seminais de Wallerstein (1990), Braudel (1992) e Wolf (1982) em torno do sistema mundial moderno e da economia-mundo capitalista -, a etnografia teria de escapar aos cânones clássicos - um lugar, uma comunidade, um espaço sociogeográfico circunscrito e praticamente apartado dos demais - para assumir uma multiplicidade de lugares, ainda que Manjacaze se afigure como central. Sendo eleitas como principais referências as teorias do sistema mundial e considerando as teses de Olivier de Sardan, optou-se por uma estratégia de compreensão e análise que se opõe às velhas tradições antropológicas, como o culturalismo, que nada nos diz sobre as forças que comandam as interações entre as sociedades desde o final do século XV, como sublinha Wolf (ibidem:4-5) ao nos propor uma antropologia diferente, capaz de apreender as conexões e as dependências entre diferentes culturas no quadro do sistema mundial.

Este artigo tem início com a apresentação da estratégia metodológica que organizou o trabalho no terreno, avançando depois para a discussão do trajeto histórico da indústria do caju em Moçambique. Finalmente, são analisados o desmantelamento da empresa estatal de produção de caju e a reorganização a que o setor é sujeito no contexto do aprofundamento da integração do país no sistema global capitalista. Tendo como pano de fundo a utilização flexível de diversas técnicas observação participante, inquérito por questionário e pesquisa documental -, o presente texto se baseia na exploração de fontes documentais e bibliográficas, e em entrevistas e diálogos informais com os mais diversos informantes, sem os quais não teria sido possível construir a 
narrativa e esclarecer muitos aspectos que, por diversas razões, não foram fixados em documentos escritos ${ }^{2}$. Essa estratégia facilitou não só a organização da reflexão sobre os principais fatos e atores sociais envolvidos como também a própria análise sobre o modo como as dinâmicas e tendências estruturais de dimensão sistêmica condicionam e interagem com os quadros político e socioeconômico nacionais.

\section{TRABALHO DE CAMPO E PRODUÇÃO DE ETNOGRAFIAS GLOBAIS}

Perante a explosão da sociedade tradicional, como reconhece Geertz (1992), Wolf (1982:390-391) argumenta que não podemos pensar mais nas sociedades como sistemas auto-sustentados e isolados, tampouco imaginar culturas como totalidades integradas e autônomas. Daqui decorrem várias conseqüências em termos metodológicos. As abordagens clássicas, centradas no estudo intensivo e praticamente exclusivo de um lugar e de uma comunidade, não são capazes de dar conta da teia densa de relações sociais que se estabelece e da força que as estruturas exercem sobre a vida cotidiana. Assim, buscou-se fazer uma "etnografia global", de acordo com a definição de Burawoy et alii (2000): uma etnografia simultaneamente atenta, por um lado, às estruturas e aos processos de dimensão mundial; por outro, aos cotidianos de vida dos homens e das mulheres, notadamente nos espaços de produção. Considerando os impactos nos processos de mudança social provocados pela industrialização na África, foram seguidas as propostas formuladas por Wolf $(1982 ; 2001)$ em prol de uma antropologia mais histórica. Trata-se de articular os modos de vida e de trabalho dos atores sociais observados com as estruturas econômicas e políticas que comandam os Estados e os mercados, como sustenta Wolf (2001:335).

Observando o lugar ocupado pelas fábricas onde se realizou parte significativa da pesquisa, é necessário mencionar a influência exercida pelos trabalhos de antropologia e de sociologia da empresa e os estudos sobre os operários nas fábricas (cf. Bazin, 2001; Selim, 2001; Burawoy, 1979; Estanque, 2000; Lazarus, 2001; Flamant e Jeudy-Ballini, 2002; Durão, 2003; Granjo, 2003; 2004), sobretudo no que se relaciona com a identificação e a compreensão das dimensões políticas da organização da produção e das relações sociais no interior das empresas.

O trabalho de campo é feito sempre em uma situação histórica concreta, em um espaço e tempo em que as vidas individuais e coletivas se consomem. Isso implica que o ator social que investiga tenha de escolher 
um ou mais lugares para levar a cabo o trabalho. A vinculação ao terreno não decorre somente de uma exigência metodológica relacionada, no caso da antropologia social, com o auto-reconhecimento de uma disciplina fluida e aberta em termos teóricos (Clifford, 1999:79-81). É algo mais profundo: compreender o presente dos homens e das mulheres, em particular o modo como enfrentam as rupturas que preenchem seus cotidianos, exige que se vá para o terreno partilhar nossa vida com a vida dos que colocamos sob escrutínio. Ao privilegiarem-se os pontos de vista e as práticas dos atores sociais observados, suas lógicas e constrangimentos, como defende Olivier de Sardan (2001:243-245), facilita-se o aparecimento da dúvida, essencial para pôr em questão os discursos e os pontos de vista dominantes. Quer dizer, é a brecha intelectual por meio da qual se torna possível a crítica aos modelos hegemônicos que pretendem universalizar uma cultura e um modo de vida particulares.

Essa relação com os outros constitui a marca perene do modo como o pesquisador compreende a realidade social. A um ritmo lento, que muitas vezes pode ser entendido como enfadonho, faz-se a imersão empática através da qual atingimos a compreensão dos comportamentos e expectativas dos atores sociais observados. Esse olhar sobre o trabalho de campo, que pode ser entendido como uma declinação contemplativa das subjetividades do autor, é essencial para conduzir "à objetivação do conhecimento do sujeito que busca compreender" (Bourdieu, 1992:151, tradução do autor) e à recolocação do trabalho de campo na posição adequada: "a da construção da representação de uma realidade social", como justamente exprime Bourdieu em sua crítica à "concepção positivista do trabalho científico e de uma ciência sem sujeitos", cujo paradigma na antropologia contemporânea é o "'positivismo renovado' de Clifford Geertz, baseado na exaltação do particularismo e do 'conhecimento local'"' (ibidem, tradução do autor).

\section{INDUSTRIALIZAÇÃO DA CASTANHA DE CAJU: TRAJETO HISTÓRICO}

O caju foi um dos primeiros produtos agrícolas em Moçambique a conectar-se com a economia-mundo capitalista. Datam do início do século XX as exportações para a Índia de castanha de caju in natura (cf. Ohler, 1979). Com uma presença secular nas zonas litorais do território moçambicano, o comércio da castanha foi controlado por comerciantes de origem indiana. Apesar de muitos deles pertencerem a famílias fixadas em Moçambique desde meados do século XIX, os vínculos com 
suas terras de origem permaneceram sempre bem vivos, sobretudo no que dizia respeito à língua e à religião. Sendo a Índia o único processador mundial de caju, naturalmente esses comerciantes mobilizaram seus recursos relacionais para assegurar, em Moçambique, o domínio sobre as rotas de comercialização e de acesso ao mercado indiano (cf. Spence, 1963; Leite, 1995; 2000).

A partir dos anos 1950, o poder político e a burguesia colonial portuguesa começaram a considerar desvantajosa a exportação da castanha in natura em relação a seu processamento e posterior colocação no mercado internacional. O que estava em causa, como observou Joana Pereira Leite (1995), era o corte com a complementaridade entre Moçambique e Índia nesse setor econômico. A Índia possuía mão-de-obra abundante, submetida a uma eficiente organização do trabalho orientada para o descasque manual da castanha, a fase mais árdua e a que mais força de trabalho exigia. Diante desse cenário, a saída possível para a industrialização era enveredar, por meio da mobilização de quantidades avultadas de capital, pelo desenvolvimento de equipamentos mecânicos, tal como foi reconhecido e sugerido por agências da Organização das Nações Unidas - ONU à administração colonial portuguesa e aos eventuais investidores (conforme (L')Agriculture et les Industries de Transformation au Mozambique, relatório produzido pela ONU).

A expansão industrial dar-se-ia em meados da década de 1960, impulsionada pela entrada do grande capital português (Companhia União Fabril - CUF) e internacional (Anglo American, com sede na África do $\mathrm{Sul}$ ), fato que sinalizava inequivocamente o interesse e as expectativas, nessa conjuntura, dos grandes investidores na realização de mais-valias nesse setor industrial emergente ${ }^{3}$. Na divisão internacional do trabalho, caberia a essa indústria o descasque da castanha de caju, ficando a comercialização a cargo de empresas dos países centrais. A consolidação desse setor não foi isenta de alguma turbulência. Vivendo ainda a idade da infância, os equipamentos mecânicos de descasque - por impacto ou corte por lâminas - impuseram dificuldades à indústria, demandando esforços contínuos na pesquisa de novas soluções. Apesar das dificuldades técnicas, o setor estava largamente consolidado em 1975, por ocasião da independência moçambicana.

Uma das fábricas que faz parte desse trajeto é a de Manjacaze, localizada a escassos 1.500 metros do centro dessa vila de grande importância na história do nacionalismo e da formação do Estado moçambicano (cf. 
Ribeiro, 2005). Foi construída por iniciativa de um colono português, Manuel Rodrigues Neto, natural do Algarve, que chega a Moçambique em agosto de 1949. Em 1962, Rodrigues Neto instala a fábrica com o apoio explícito do governador-geral, que o incentivara a empenhar-se em um projeto industrial em uma zona rural:

O que me levou a ir para Manjacaze foi o Almirante Sarmento Rodrigues. Não houve política nenhuma. Foram as necessidades do governo. Sempre gostei de Manjacaze, nunca tive problemas, de forma que gostava de estar ali. Quando a gente se convence que aquilo seria um grande negócio, não só para mim como para muita gente de Manjacaze... (Manuel Rodrigues Neto em entrevista ao autor, janeiro de 2002).

Depois de começar por partir a castanha a martelo, Rodrigues Neto passou, no início dos anos 1970, para o descasque mecânico por impacto, que procurou desenvolver até outubro de 1975, quando partiu definitivamente para Portugal.

Com a saída dos colonos proprietários, as fábricas de castanha de caju passam a ser geridas por comissões administrativas. Em 1977, essas experiências de autogestão dão lugar a órgãos de direção nomeados pelo Estado. Finalmente, em 1979, é constituída uma única empresa - a Caju de Moçambique - para gerir, praticamente de forma exclusiva, o setor industrial do caju. Para além das dificuldades provocadas pela guerra e pela carência de técnicos qualificados para supervisionar os complexos equipamentos de descasque mecânico, a Caju de Moçambique esteve sempre sujeita às dinâmicas do sistema capitalista global. Sendo uma empresa conectada com o mercado mundial, a oscilação dos preços e da procura condicionava-a fortemente. Mantendo a dependência, já presente no período colonial, em relação ao mercado norte-americano, principal consumidor mundial de amêndoa de caju, a Caju de Moçambique sobreviveu ao longo dos anos 1980 explorando com algum engenho a luta que opunha os países capitalistas ao bloco liderado pela União Soviética. Em um contexto de hostilidade exacerbada da administração norte-americana liderada por Reagan, a empresa estatal conseguiu manter abertos os canais e fluxos comerciais com os Estados Unidos, para onde vendiam as amêndoas com valor comercial superior: brancas e inteiras, de preferência de grades maiores. Ao mesmo tempo, servindo-se das relações preferenciais e dos acordos comerciais e de cooperação estabelecidos, exportava para os países europeus do bloco socialista as amêndoas de menor valor comercial: ama- 
relas e partidas, em suas múltiplas variedades. Designados por sistema barter ${ }^{4}$,

[...] estes acordos fixavam apenas quantidades de amêndoa a exportar sem especificar os preços e os grades. Grande parte das solicitações destes países era de amêndoas partidas, para utilizações na confeitaria. Esses países não eram muito "dados" à discussão do preço, deixando isso ao critério do vendedor. Conseguia-se deste modo vender amêndoas partidas com "prémio", diminuindo a diferença do seu preço com relação às "inteiras", gerando a tendência natural de destinar as "inteiras" ao ocidente e as "partidas" ao leste (Incaju, 1999:34).

Com a adesão de Moçambique às instituições de Bretton Woods em meados da década de 1980, bem antes do colapso a leste, surgem novas dificuldades para a empresa estatal. Entrando em cena, o Banco Mundial - BM não perdeu tempo em colocar suas "cartas na mesa", exigindo que, entre outros aspectos, parte dos financiamentos e dos empréstimos - mesmo quando concedidos por outras instituições, como o Banco Africano de Desenvolvimento - fosse destinada ao setor privado. Com a crise irreversível a leste, Moçambique reintroduziu o sistema de mercado capitalista, fato que, inevitavelmente, repercutiria na Caju de Moçambique. No início da última década do século XX, essa empresa estava já em graves dificuldades. A guerra havia perturbado severamente o setor, desarticulando a cadeia produtiva desde a apanha até o transporte da castanha para as unidades de produção, passando por sua comercialização. Algumas fábricas, como as de Manjacaze e de Namacurra (província da Zambézia), foram alvo de ataques por parte da Resistência Nacional Moçambicana - Renamo. Em quase todas foi necessário dar treino militar aos operários para organizá-los em milícias de defesa das instalações fabris.

No âmbito econômico, anunciava-se a privatização do setor empresarial do Estado ${ }^{5}$. Tal como todos os outros quadros dirigentes, os membros da direção central da Caju de Moçambique e, em especial, seu responsável máximo anteviram o que se passaria. Como referiu esse gestor, "a música que estava a tocar era outra". Desaparecida a União Soviética e com a indústria de caju necessitando de novos investimentos para a recuperação de edifícios e equipamentos, era imperioso procurar alternativas. Fazendo uma retrospectiva desse doloroso processo, Marcelino dos Santos afirmou: 


\section{Fernando Bessa Ribeiro}

Sentimos que ficávamos [sozinhos] a braços com as forças do imperialismo. Os nossos ministros olham para as privatizações como a coisa mais bela que o paraíso jamais fecundou. Por quê? Para imporem as imposições do Fundo Monetário Nacional não é preciso cobri-las com papel dourado. Quando as dificuldades caíram sobre os trabalhadores, tivemos muitas dificuldades em lhes explicar. Porque nós já tínhamos dito que era uma coisa bela (entrevista ao autor no Comitê Central da Frente de Libertação de Moçambique - Frelimo, agosto de 2001).

Como "um pobre não pode escolher quem lhe dá esmola" ${ }^{6}$, deu-se a subordinação às instituições de Bretton Woods, a que Moçambique pertencia desde 1984. Como bem exprime Vasconcelos, em seu tom acre, a dependência manifestava-se também sob a forma de obediência dos governantes, que nada mais faziam além de escutar as instruções sobre o modo como Moçambique devia agir "com os bancos, o petróleo, a terra, os caminhos-de-ferro, as linhas aéreas, as indústrias, a alfândega, o orçamento, os impostos, a polícia, o exército, os tribunais..." (1999:25). Como estaria claro para a direção política da Frelimo, apenas a guerra impediu que as privatizações se iniciassem mais cedo, talvez mesmo uma década antes.

\section{ENTRE MARTELOS E LÂMINAS: PRIVATIZAÇÃO E DEBATE TECNOLÓGICO}

A destruição da empresa estatal Caju de Moçambique e a alienação a retalho de suas fábricas, na segunda metade dos anos 1990, ocorreram em um contexto dominado pela ingerência manifesta das instituições do Consenso de Washington na política moçambicana ${ }^{7}$. A privatização da Caju de Moçambique se beneficiou da colaboração de instituições internacionais aparentemente não comprometidas com o neoliberalismo, como a Food and Agriculture Organization of the United Nations -FAO. Em um relatório publicado em 1991 - Assistance to the Rehabilitation of the Cashew Sector, Mozambique -, essa estrutura da ONU faz um inventário detalhado da situação das fábricas de caju em Moçambique. Os consultores da FAO apresentaram como problemas maiores as deficiências de gestão (concentração excessiva de autoridade no delegado executivo, no âmbito da unidade de produção, escassez de gestores e de chefias intermediárias), pessoal técnico em número insuficiente e coexistência de diversos sistemas tecnológicos, com exigências relevantes em termos de manutenção técnica e de importação de peças de substituição. Se é verdade que o setor se confrontava com uma grande diversidade de sistemas tecnológicos, tal não ocorria 
com as fábricas da Caju de Moçambique, nas quais era utilizado exclusivamente o sistema de descasque por impacto.

Essa orientação da FAO colocava em causa os sistemas produtivos assentes em capital intensivo e em tecnologias complexas utilizados pela Caju de Moçambique. Daí a proposta de um novo sistema de processamento: o Steam Heating Cutting System - SHCS, vulgarmente designado como sistema indiano ${ }^{8}$, baseado no cozimento da castanha por vapor de água em associação com o corte da casca por meio de máquinas de lâminas de acionamento manual (cf. Figura 1). Em sua fundamentação, não foram considerados de forma adequada diversos aspectos relevantes para compreender as dificuldades que afetavam a indústria do caju: o ambiente sociopolítico em que as fábricas haviam operado, dominado pela guerra, pelo deslocamento das populações, pelas dificuldades na apanha e na comercialização da castanha de caju; e a cultura técnica e de trabalho com mais de três décadas de experiências e saberes acumulados. Enfim, ao indicar a falta de viabilidade dos sistemas mecânicos de descasque, a FAO estava implicitamente declarando que a Caju de Moçambique não tinha futuro? .

Se é certo que a eficiência produtiva dos diferentes sistemas técnicos (cf. Quadro 1) não pode ser ignorada, a escolha não é apenas por ela determinada. Como justamente refere Geslin (1999:7-9), na esteira do argumento desenvolvido por Martinelli (1987), a escolha técnica tem uma dimensão social à qual não pode escapar e que importa examinar para melhor compreendê-la. Apoiando-se nos contributos decisivos produzidos pelos teóricos da Escola de Frankfurt (cf. Habermas, 1994),

Figura 1

Sistemas Técnicos de Descasque de Castanha de Caju

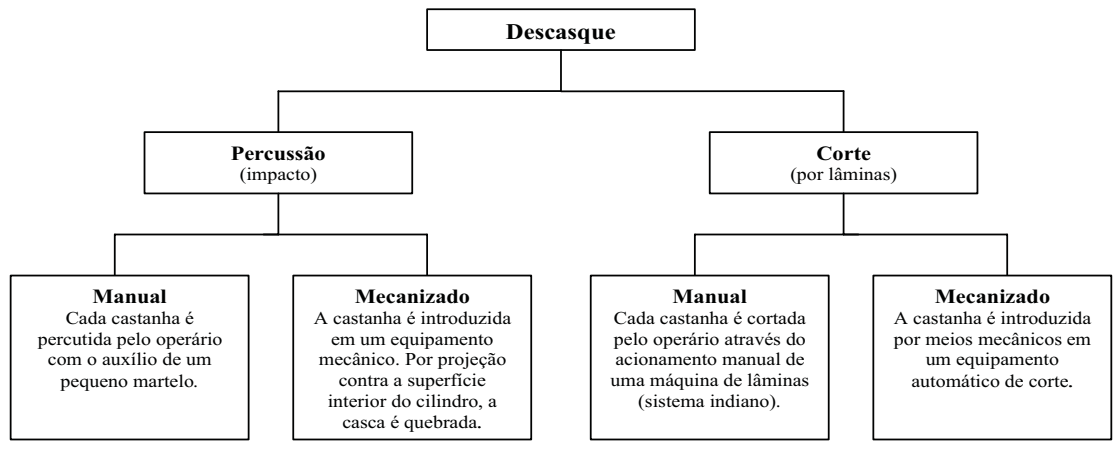

Elaboração do autor. 
Ivonaldo Leite (2005:46) salienta que os interesses e objetivos sociais, em especial os dos grupos dominantes, estão já inseridos nas escolhas técnicas pelo que nelas se projeta o que dada sociedade, em um contexto histórico concreto, pretende fazer com os indivíduos e os objetos materiais. Nesse sentido, Harvey (1999:100) mostra-nos que as técnicas e as tecnologias são a forma material do processo de trabalho por meio da qual as forças produtivas e as relações de produção se exprimem. Longe de serem socialmente neutras, sublinha Martinelli (1987:321-322), ambas têm um enorme impacto na organização do trabalho e estão indissoluvelmente ligadas às lutas sociais e às relações de força que opõem os trabalhadores ao capital e aos conflitos que ocorrem nos espaços de produção (Burawoy, 1979). Quer dizer, as escolhas técnicas não podem ser desconectadas das mudanças sociais e das estruturas no interior das quais fazem sentir seus efeitos, nem sua crítica pode ser separada da crítica das formas organizacionais engendradas nos espaços de produção. Elas são inseparáveis das políticas de produção, notadamente do modo como se regula o trabalho no espaço de produção e do papel que nele desempenham os operários. Como os capitalistas não operam no vazio - antes, confrontam-se cotidianamente com diversos constrangimentos, como a luta de classes, os limites do conhecimento tecnocientífico e os custos com a substituição dos equipamentos ou sua simples operação e manutenção-, as escolhas técnicas constituem um recurso precioso para o capital em sua procura permanente por melhores condições para a realização de mais-valias (Harvey, 1999:117-124).

Quadro 1

Sistemas de Descasque de Castanha de Caju - Síntese Comparativa

\begin{tabular}{|l|c|c|c|}
\hline \multicolumn{1}{|c|}{$\begin{array}{c}\text { Sistema de } \\
\text { Descasque }\end{array}$} & $\begin{array}{c}\text { Valor do Investimen- } \\
\text { to em Equipamento }\end{array}$ & $\begin{array}{c}\text { Capacidade Ideal } \\
\text { de Processamento } \\
\text { Anual (em t) }\end{array}$ & $\begin{array}{c}\text { \% de Amêndoa } \\
\text { Inteira Embalada }\end{array}$ \\
\hline Martelo & $20.000 €$ & 300 & $60-65$ \\
\hline Corte semimecânico & $80.000 €$ & $600-1.000$ & $60-70$ \\
\hline Impacto mecanizado & $700.000 €$ por $1.000 \mathrm{t}$ & $2.500-5.000$ & $50-55$ \\
\hline Corte mecanizado & $750.000 €$ por $1.000 \mathrm{t}$ & $3.500-10.000$ & $50-60$ \\
\hline
\end{tabular}

Fonte: Deloitte \& Touche ILA (1997).

As escolhas técnicas não implicam, de forma mecânica, a intensificação e a complexificação dos processos produtivos. De fato, não se pode 
esquecer que é "o carácter mercadoria do produto" (Palloix, 1974:208) o que interessa ao capital, isto é, não interessa o modo como se produz, mas sim o que se produz. Não sendo o modo como se produz um fim em si mesmo, mas simplesmente um meio para a reprodução alargada do capital, no caso da indústria do caju, o que realmente importa é a amêndoa de caju, e não as técnicas e os processos utilizados para chegar até ela. Quer dizer, os sistemas produtivos complexos, nas condições em que o processamento do caju em Moçambique se realiza atualmente, não trazem qualquer vantagem para os detentores do capital. Em face da desregulação das relações de trabalho, da abundância de mão-deobra e da lentidão da recuperação do capital investido em equipamentos, a forma mais rápida para obtenção de mais-valias assenta na utilização intensiva da força de trabalho - o capital variável da esfera produtiva que mais próximo se encontra do capital-dinheiro, precisamente aquele que, na fórmula geral de Marx (1974) [1867], significa "liquidez, flexibilidade e liberdade de escolha" (Arrighi, 1996:5). Tal como ocorria no século XIX com as mulheres inglesas que puxavam os barcos nos canais, em determinadas circunstâncias o investimento em artefatos e em outros meios de produção pode não se justificar ante o custo diminuto dos salários pagos aos trabalhadores.

Privatizadas as fábricas, o golpe decisivo na indústria do caju foi dado pelo BM, ao impor ao governo moçambicano, no âmbito do Country Assistance Strategy - CAS ${ }^{10}$, a introdução de medidas liberalizadoras para exportação de castanha de caju ${ }^{11}$ como contrapartida à disponibilização dos créditos de que o país carecia para a reconstrução:

Nós percebemos que o governo estava entalado. Assinou coisas que nunca deveria ter assinado. Assinou sem ter percebido as conseqüências. O governo foi chantageado pelo BM, que fez depender a libertação do crédito da liberalização da exportação de castanha. Esperávamos que o governo encontrasse conosco uma solução, não aceitando a eliminação da sobretaxa [sobre a castanha in natura exportada]. Nós éramos o segundo maior exportador de amêndoa a seguir à Índia, agora não contamos nada. Eles fizeram o favor de nos tirar do mapa. Vejamos o açúcar. Faz-se a privatização, e o BM vem dizer que pode haver sobretaxa [sobre a exportação de açúcar]. Como o capital é estrangeiro, existem outras formas de pressão, os governos da nacionalidade do capital defendem os interesses destes (proprietário de uma fábrica da Caju de Moçambique, antigo membro da burocracia estatal, em entrevista ao autor, junho de 2001) $)^{12}$. 
Corroborando essa posição, em 1997 o ministro responsável pela área industrial referiu, no Parlamento, que o governo havia sido colocado "contra a parede" pelo BM, pelo que foi preciso escolher entre, no seu entender, os interesses gerais do país e os interesses relacionados à indústria de processamento de castanha (cf. Metical, no 114, 4/12/1997). Sendo certo que o governo moçambicano foi sujeito a uma forte pressão, sob a ameaça da asfixia financeira, importa salientar também que o BM contou com seus aliados locais, não raro dependentes dele como consultores. Formados em universidades americanas, nomeadamente no Departamento de Agricultura Econômica da Universidade Estadual de Michigan, agem como "cavalos de Tróia" do neoliberalismo, marcando presença em diversos ministérios, cabendo-lhes uma parte substancial do trabalho de organização e preparação de relatórios e outros documentos essenciais à tomada de decisões políticas por parte dos titulares das pastas. Nas publicações acadêmicas, muitas delas baseadas em investigações financiadas pela Agência dos Estados Unidos para o Desenvolvimento Internacional - Usaid, e nas intervenções públicas, as teses neoliberais são defendidas com veemência (cf., entre outros, Marrule et alii, 1999; Mole e Weber, 1999 e Low et alii, 2001). Assim, a dependência do aparelho de Estado moçambicano não é apenas financeira; é também técnica e ideológica.

É necessário considerar ainda o papel desempenhado pelo direito na introdução e na consolidação de mudanças políticas e sociais nas sociedades modernas ${ }^{13}$. A produção de um vasto acervo legislativo deu enquadramento legal e legitimidade política às práticas que conduziram não só à destruição da Caju de Moçambique como também ao desmantelamento da organização industrial, cujas origens remontam ao período colonial. A própria utilização intensiva da força de trabalho baseada no trabalho à tarefa é inseparável de um novo ordenamento jurídico e legislativo. Foi ele que permitiu tornar legal e, de certa forma, "naturalizar" a hiperflexibilização, adotando designadamente um regulamento ordenador do trabalho rural que possibilitou a remoção de todos os estorvos legais ao trabalho à tarefa, flexível e conforme às necessidades da indústria, esmagando-se assim os custos salariais de que dependia a viabilidade dos sistemas produtivos simples. Trata-se de levar o salariato a seu limite extremo, o da máxima flexibilidade, que admite a todo o tempo a dispensa do trabalhador. Mas não só: como argumenta Meillassoux (1997:13 e ss.), esse regime salarial, dominante nos países periféricos, configura uma situação de sobreexploração do trabalho, isto é, de captação da substance vivante do trabalhador por via 
da diminuição da saúde em virtude de doenças profissionais, violação da integridade física, sob a forma de acidentes de trabalho, e redução da esperança de vida, enfim, formas de extração do lucro, por meio da mutilação da vida do operário, que escapam ao cálculo salarial da empresa.

Na transição do século, as fábricas privatizadas estavam todas paradas ou em funcionamento parcial e intermitente. O grupo de investidores que as controlava, saído da burocracia estatal, foi derrotado pelos que, no interior do aparelho de Estado e vinculados a empresas comerciais, em sua maioria controladas por famílias de origem indiana, tinham interesse na exportação de castanha de caju in natura para o mercado indiano (cf. Savana, no 597, 13/6/1997).

É nesse novo contexto político e econômico que surgem as pequenas unidades de processamento de castanha de caju. Seu triunfo é conseqüência direta das condições que favorecem o esmagamento dos salários e o aumento desmesurado da disponibilidade de força de trabalho em Moçambique, tornando supérfluo, ou não-econômico, segundo a racionalidade liberal, o investimento em capital fixo. Procurando tirar proveito dessa nova correlação de forças entre o capital e o trabalho e do ambiente internacional favorável, outro segmento da burguesia moçambicana - também ele saído, em boa parte, da burocracia estataldecidiu substituir a inovação técnica, enquanto mecanismo fundamental da acumulação, pela compressão dos custos salariais e a redução brutal de investimentos em máquinas e equipamentos de produção. É o caso da fábrica de Jongué, localizada no distrito de Manjacaze, a cerca de 20 quilômetros de sua sede administrativa. Entre outros aspectos, essa pequena unidade industrial em meio rural nos revela um dos modos de atuação da elite político-burocrática moçambicana na luta pela acumulação de propriedade e capital: a criação de uma empresa de raiz em um setor considerado promissor pelos consultores ao serviço do BM. Assim, a origem da fábrica está estreitamente ligada às opções políticas impostas pelas instituições do Consenso de Washington e adotadas pelo governo moçambicano, ou seja, disposições que, no quadro das estruturas dominantes, condicionam as oportunidades e as escolhas dos atores sociais. Essa fábrica é um exemplo paradigmático da resposta empresarial encontrada pela elite local para manobrar em seu proveito as possibilidades oferecidas pelo novo quadro socioeconômico produzido pelas políticas de "ajustamento estrutural". 
O responsável por essa iniciativa é um membro da segunda geração da elite dirigente do país que paulatinamente tem ocupado lugares no aparelho de Estado e afastado a velha elite formada na luta armada. Seu trajeto político e profissional faz dele um caso ilustrativo do que é designado por Pitcher (2003:813) como os "novos capitalistas": antigos membros do governo ou ex-gestores das empresas estatais que, servindo-se de seus contatos privilegiados no aparelho de Estado, adquiriram a propriedade de fábricas e outras unidades de produção alienadas ou formaram novas empresas. Sua carreira política e profissional é comum à dos jovens tecnocratas da Frelimo mais bem-sucedidos. Licenciado em economia, foi gestor em uma empresa estatal, posteriormente governador de província. Em meados da década de 1990, passa a ministro da Agricultura. Conhecendo de perto os dossiês produzidos pelos consultores que apontavam como alternativa às grandes fábricas mecanizadas a pequena indústria baseada na utilização de mão-deobra intensiva e de sistemas técnicos simples, decidiu explorar em seu proveito as oportunidades proporcionadas pelo cargo exercido para montar sua empresa. No entanto, a condição de ministro impunha alguns obstáculos políticos, que pensou contornar por meio de uma manobra jurídica hábil e relativamente freqüente: manter o controle da empresa sem estar formalmente comprometido com ela. Assim, caberia à esposa e aos filhos a responsabilidade jurídica na sociedade por cotas, constituída em setembro de 1996 e com sede em Maputo. Um burocrata empreendedor? Certamente. Com formação acadêmica de nível superior, experiência feita na burocracia e nas empresas estatais, soube mobilizar seus próprios recursos - algum capital e conhecimentos empresariais - e os do Estado, jogando com habilidade as "cartas" do poder político e as redes clientelares que gravitam em torno deste.

A fábrica foi construída em 1997 com base em um estudo de viabilidade econômica elaborado por um consultor com larga experiência no setor, antigo dirigente da Caju de Moçambique. Essa fábrica, cujo sistema produtivo conjuga mão-de-obra intensiva com artefatos mecânicos simples do SHCS, é uma expressão concreta das mudanças técnicas verificadas com a recomposição da indústria do caju na década de 1990. Como aconteceu com outras fábricas instaladas nessa época em Moçambique, o projeto seguiu de perto as propostas do BM, da FAO e de outras instituições internacionais com trabalho feito na área do caju. 


\section{CONSIDERAÇÕES FINAIS}

Desde suas origens que o capitalismo é feito não só de expansão e mudança mas também de lutas entre Estados, entre o centro e as periferias, entre dominantes e dominados. Suas reconfigurações, inseparáveis da mudança nos regimes de acumulação, são produto desses conflitos intermináveis travados também no âmbito estatal e nos mais diversos campos da vida social. É o caso da economia do caju. Na configuração atual, ela exprime, por um lado, o triunfo dos interesses da burguesia comercial e das elites políticas interessadas na obtenção acelerada de rendimentos; por outro, as dinâmicas sistêmicas que acentuaram as relações de dependência de Moçambique no interior da economia-mundo capitalista. É nesse contexto que a posição da Índia - país periférico em termos sistêmicos, mas central na economia mundial do caju - se reforçou, recolocando Moçambique em uma situação muito semelhante à posição ocupada até os anos 1950. As pequenas fábricas e as mudanças tecnológicas associadas a elas são conseqüência direta das novas condições econômicas que favorecem o esmagamento dos salários e o aumento desmesurado da disponibilidade de força de trabalho em Moçambique. Explorando uma alteração profunda na correlação de forças entre o capital e o trabalho - provocada por um incremento muito substancial da quantidade de força de trabalho disponível, pelo crescimento da produção facilitada pelo desenvolvimento das tecnociências em outros países periféricos concorrentes, como Brasil e Índia, e, em menor importância, por uma oferta crescente dos produtos de substituição criados pelas indústrias alimentares -, o capital na indústria de caju em Moçambique trocou, como mecanismo fundamental da acumulação e eventualmente de modo transitório, a inovação técnica pela compressão dos custos salariais e a redução dos investimentos em máquinas e equipamentos de produção.

O encerramento das velhas unidades de processamento de castanha de caju, não compensado com o aparecimento das fábricas baseadas no SHCS, empurrou para o desemprego milhares de trabalhadores. O impacto social foi particularmente grave nos pequenos aglomerados urbanos, como Manjacaze, com poucas alternativas de trabalho assalariado e muito dependente dos salários auferidos pelos operários para a dinamização dos circuitos monetários locais. O salariato é decisivo para o acesso regular, se bem que marginal, dos operários e de suas famílias às trocas de mercado, atenuando a dependência extrema em relação à terra e aos ganhos - sempre incertos - proporcionados pela ven- 
da dos pequenos excedentes da produção agrícola. Viver nas atuais circunstâncias fora dos circuitos monetários e das trocas de mercado implica um cotidiano ferido por privações extremas e uma fruição muito limitada de determinados bens e serviços, aos quais só é possível aceder por meio do poder de compra proporcionado pela moeda. A situação é particularmente crítica no caso do caju não só pelo colapso da indústria ter ocorrido em um contexto de definhamento geral do trabalho assalariado como também por muitas das fábricas estarem situadas em pequenas áreas urbanas fortemente ligadas às atividades agrícolas, onde elas asseguravam a função crucial de dinamização da circulação monetária.

Em suma, nessa produção, destruição e reconfiguração permanente do espaço-tempo mundial, quer intra, quer interpaíses, da qual depende a dinâmica do capitalismo (Harvey, 1999:XXV), a posição de Moçambique é particularmente difícil. Nessas circunstâncias, dificilmente se consegue escapar ao afro-pessimismo, sobretudo quando se confronta o presente com o passado próximo desse país, marcado pelo otimismo e por grandes esperanças, quiçá desmedidas e pouco prudentes, da elite política que conduziu a luta contra o colonialismo português e governou no período revolucionário pós-Independência.

(Recebido para publicação em novembro de 2007)

(Versão definitiva em maio de 2008) 


\section{NOTAS}

1. Olivier de Sardan (1995:6) considera que essa vasta área transdisciplinar pode contribuir para a renovação das ciências sociais. Tal argumento retoma a tese de Lévi-Strauss (1996) sobre a contínua recriação dos velhos terrenos em contraponto à idéia, que está longe de ser recente, do esgotamento das temáticas coloniais e rurais (cf. Granjo, 1998).

2. Muitos dados foram fornecidos por informantes que solicitaram a máxima confidencialidade. Assim, estes não são identificados para que sejam resguardados de eventuais inconvenientes provocados por seus testemunhos.

3. Esse desenvolvimento industrial tardio é mais um exemplo da debilidade do colonialismo português, que deve ser compreendida considerando a situação semiperiférica de Portugal (cf. Santos, 1993). A escassez de recursos demográficos, econômicos, militares e outros condicionou fortemente a intervenção no território moçambicano.

4. Troca de bens por bens. Moçambique recebia bens e matérias-primas de seus parceiros do leste europeu, nomeadamente petróleo e equipamentos industriais e de transporte. Para a amêndoa de caju, o valor das exportações sob esse regime nunca excedeu os 30\% do volume de negócios da Caju de Moçambique (informação verbal concedida ao autor pelo último diretor geral da empresa).

5. Para uma perspectiva geral, na ótica do BM, da privatização do aparelho produtivo estatal nos países socialistas, ver Lee e Nellis (1990).

6. Esse ponto de vista foi enunciado por um antigo responsável da Caju de Moçambique, em entrevista ao autor realizada na cidade de Maputo em setembro de 2001.

7. O Consenso de Washington visa ao estabelecimento de uma economia global baseada no mercado livre e na iniciativa privada. Para a hegemonia dessa agenda política, contribuiu o aturado e paciente trabalho levado a cabo pelos think tanks liberais, que nunca dela desistiram, mesmo nas décadas pós-Segunda Guerra Mundial, marcadas pelo domínio praticamente inquestionado das teses keynesianas (cf. Dixon, 1999).

8. Esse foi o primeiro documento em que aparece inequivocamente formulada a proposta de adoção do SHCS. Como se verá, esse sistema tecnológico assenta sua competitividade nos baixos salários e na sujeição dos operários a ritmos de trabalho brutais, penosos e, a médio prazo, incapacitantes.

9. Se a empresa estatal era o alvo, essa nova orientação questionava também as empresas com sistemas tecnológicos complexos que permaneceram na posse do capital privado durante o período revolucionário, como a fábrica da Anglo American no Xai-Xai (capital da província de Gaza).

10. Documento em que o BM expõe sua estratégia para o país beneficiário.

11. Proibida desde 1975, a exportação de castanha in natura foi autorizada a partir de 1991 (cf. Leite, 2000).

12. O entrevistado refere-se à açucareira da Companhia de Sena, de capitais majoritariamente mauricianos. Antiga Sena Sugar Estates, foi até a década de 1980 a maior empresa produtora de açúcar de Moçambique. Localizada em uma zona de intensa atividade da Renamo, encontrava-se, desde essa época, encerrada, até que a chegada dos investidores das Maurícias permitiu sua reconstrução e o reinício das operações industriais (Metical, no 756, 19/6/2000).

13. Refletindo sobre os tribunais e a democratização da justiça em Portugal, Santos (1994:141 e ss.) oferece elementos fundamentais para se compreender o lugar do direito nas sociedades capitalistas. 


\section{REFERÊNCIAS BIBLIOGRÁFICAS}

ARRIGHI, Giovanni. (1996), O Longo Século XX: Dinheiro, Poder e as Origens do Nosso Tempo. São Paulo, Editora Unesp.

BAZIN, Laurent. (2001), "Industrialisation, Désindustrialisation", in L. Bazin e M. Selim, Motifs Économiques en Anthropologie. Paris, L'Harmattan, pp. 111-154 (com a colaboração de Gérard Althabe).

BOURDIEU, Pierre. (1992), "Posfácio", in P. Rabinow, Reflexiones sobre un Trabajo de Campo en Marruecos. Madrid, Júcar, pp. 151-153.

BRAUDEL, Fernand. (1992) [1979], Civilização Material, Economia e Capitalismo (Séculos XV-XVIII): O Tempo do Mundo. Lisboa, Teorema.

BURAWOY, Michael. (1979), Manufacturing Consent: Changes in the Labor Process under Monopoly Capitalism. Chicago, The University of Chicago Press.

et alii. (2000), Global Ethnography: Forces, Connections, and Imaginations in a Postmodern World. Berkeley, University of California Press.

CLIFFORD, James. (1999), Itinerarios Transculturales. Barcelona, Gedisa.

DELOITTE \& TOUCHE ILA. (1997), Estudo do Impacto da Liberalização do Mercado da Castanha do Caju em Moçambique. Relatório final, Maputo.

DIXON, Keith. (1999), Os Evangelistas do Mercado: Os Intelectuais Britânicos e o Neoliberalismo. Oeiras, Celta.

DURÃO, Susana. (2003), Oficinas e Tipógrafos: Cultura e Quotidianos de Trabalho. Lisboa, Dom Quixote.

ESTANQUE, Elísio. (2000), Entre a Fábrica e a Comunidade: Subjectividades e Práticas de Classe no Operariado do Calçado. Porto, Afrontamento.

FAO - Food and Agriculture Organization of the United Nations. (1991), Assistance to the Rehabilitation of the Cashew Sector, Mozambique. Relatório técnico (FAO-AG-TCP/MOZ/8955), Roma.

FLAMANT, Nicolas e JEUDY-BALLINI, Monique. (2002), “Le Charme Discret des Enterprises: L’Ethnologie en Milieu Industriel”. Terrain, no 39, pp. 5-16.

GEERTZ, Clifford. (1992), La Interpretación de las Culturas. Barcelona, Gedisa.

GESLIN, Philippe. (1999), L'Apprentissage des Mondes: Une Anthropologie Appliquée aux Transferts de Technologies. Paris, Éditions Octarès/Fondation de la Maison des Sciences de l'Homme.

GRANJO, Paulo. (1998), “A Antropologia e a Abordagem da Indústria e do Risco: Legitimidade e Experiência de Terreno". Etnográfica, vol. 2, no 1, pp. 73-89.

. (2003), “A Mina Desceu à Cidade: Memória Histórica e a mais Recente Indústria Moçambicana". Etnográfica, vol. 2, no 2, pp. 403-428.

. (2004), "Trabalhamos sobre um Barril de Pólvora": Homens e Perigo na Refinaria de Sines. Lisboa, Instituto de Ciências Sociais.

HABERMAS, Jürgen. (1994), Técnica e Ciência como "Ideologia". Lisboa, Edições 70.

HARVEY, David. (1999), The Limits to Capital. London, Verso. 
INCAJU - Instituto de Fomento do Caju. (1999), Plano Director do Caju. Maputo, Incaju.

LAZARUS, Sylvain. (2001), “Anthropologie Ouvrière et Enquêtes d'Usine: État des Lieux et Problematique". Ethnologie Française, vol. XXXI, no 3, pp. 389-400.

LEE, Barbara W. e NELLIS, John. (1990), Enterprise Reform and Privatization in Socialist Economies. Washington, World Bank.

LEITE, Ivonaldo Neres. (2005), “A Relação Novas Tecnologias, Mercado de Trabalho e Educação como Tema e como Problema”, in A. J. F. Calado e A. M. T. da Silva (orgs.), Cidadania no Horizonte do Trabalho: Reflexões Sócio-Históricas e Pedagógicas. João Pessoa, Idéia/Edições Fafica, pp. 43-57.

LEITE, Joana Pereira. (1995), “A Economia do Caju em Moçambique e as Relações com a Índia: Dos Anos 20 ao Fim da Época Colonial”, in J. F. do Amaral et alii (orgs.), Ensaios de Homenagem a Francisco Pereira de Moura. Lisboa, Instituto Superior de Economia e Gestão/Universidade Técnica de Lisboa, pp. 631-655.

. (2000), “A Guerra do Caju e as Relações Moçambique-Índia na Época Pós-Colonial". Lusotopie 2000, pp. 295-332.

LÉVI-STRAUSS, Claude. (1996), Raza y Cultura. Madrid, Cátedra.

LOW, Jan et alii. (2001), “A Regulamentação de Comercialização da Castanha de Caju: Como Torná-la um Instrumento Revitalizador do Sub-Sector Cajueiro em Moçambique?". Flash, no 25P.

MARRULE, Higino de et alii. (1999), "Reflections on Poverty and Prospects for Growth in the Mozambican Rural Sector". Policy Synthesis for Cooperating USAID Offices and Country Missions, no 44 .

MARTINELLI, Bruno. (1987), “La Fin et les Moyens: L'Ethnologie et l'Intervention Technologique". L'Uomo, vol. XI, no 2, pp. 319-341.

MARX, Karl. (1974) [1867], O Capital. Lisboa, Delfos, vol. I.

MEILLASSOUX, Claude. (1997), L'Économie de la Vie. Lausanne, Page Deux.

MOLE, Paulo e WEBER, Michael. (1999), “O Debate sobre o Caju em Moçambique: Que Vias Alternativas?". Flash, no $16 \mathrm{P}$.

OHLER, J. G. (1979), Cashew. Amerstedam, Koninklijk Instituut voor de Tropen.

OLIVIER DE SARDAN, Jean-Pierre. (1995), Anthropologie et Développement: Essai en Socio-Anthropologie du Changement Social. Paris, Karthala.

(2001), "Populisme Méthodologique et Populisme Idéologique en Anthropolo-

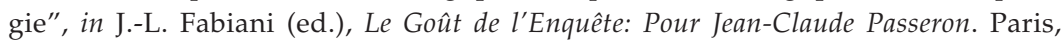
L'Harmattan, pp. 195-246.

PALLOIX, Christian. (1974), As Firmas Multinacionais e o Processo de Internacionalização. Lisboa, Estampa.

PITCHER, Anne. (2003), "Sobreviver à Transição: O Legado das Antigas Empresas Coloniais em Moçambique". Análise Social, vol. XXXVIII, no 168, pp. 793-820.

RIBEIRO, Fernando Bessa. (2004), Sistema Mundial, Manjacaze e Fábricas de Caju: Uma Etnografia das Dinâmicas do Capitalismo em Moçambique". Tese de doutorado, Universidade de Trás-os-Montes e Alto Douro, Vila Real. 


\section{Fernando Bessa Ribeiro}

. (2005), "A Invenção dos Heróis: Nação, História e Discursos de Identidade em Moçambique". Etnográfica, vol. IX, no 2, pp. 257-275.

SANTOS, Boaventura de Sousa. (1993), "O Estado, as Relações Salariais e o Bem-Estar na Semiperiferia: O Caso Português", in B. de S. Santos (org.), Portugal: Um Retrato Singular. Porto, Afrontamento, pp. 15-56.

. (1994), Pela Mão de Alice: O Social e o Político na Pós-Modernidade. Porto, Afrontamento.

SELIM, Monique. (2001), "Entreprise et Mondialisation", in L. Bazin e M. Selim, Motifs Économiques en Anthropologie. Paris, L'Harmattan, pp. 59-109 (com a colaboração de Gérard Althabe).

SPENCE, Charles Francis. (1963), Moçambique: East African Province of Portugal. Cape Town, Howard Timmins.

VASCONCELOS, Leite de. (1999), Pela Boca Morre o Peixe. Maputo, Associação dos Amigos de Leite de Vasconcelos.

WALLERSTEIN, Immanuel. (1990) [1974], O Sistema Mundial Moderno: A Agricultura Capitalista e as Origens da Economia-Mundo no Século XVI. Porto, Afrontamento.

WOLF, Eric R. (1982), Europe and the People Without History. Berkeley, University of California Press.

. (2001), Pathways of Power: Building an Anthropology of the Modern World. Berkeley, University of California Press. 


\author{
ABSTRACT \\ From Hammers to Blades: Global Dynamics and Manufacturing Policies \\ in the Cashew Industry in Mozambique
}

This article discusses how the main trends and impacts of capitalist dynamics are felt in Mozambique, based on a case study of the cashew industry, especially its industrial processing component. Having emerged in the colonial period, the cashew industry provides a practical example of Mozambique's integration in the world economy through the exploitation of natural resources and the local labor force to manufacture products for the main central markets. In order to better understand this industry's evolution and current situation, the author conducted his fieldwork in various places, especially in two cashew nut processing plants in the district of Manjacaze (Gaza Province). He thus adopted a methodological strategy based on a multilocal ethnography rather than a classical approach centered on the study of a single location or a supposedly isolated and autonomous community.

Key words: Mozambique; cashew industry; manufacturing policies

\title{
RÉSUMÉ
}

Entre Marteaux et Lames: Dynamiques Globales et Politiques de Production dans l'Industrie du Cajou

Dans cet article, on examine comment les principales tendances et impacts des dynamiques du capitalisme se présentent au Mozambique, à partir d'une étude sur l'économie du cajou, surtout dans son aspect industriel. Née dans la phase finale du colonialisme, cette industrie reflète un mode concret de l'intégration du Mozambique dans l'économie mondiale, par l'exploitation des ressources naturelles et de la force du travail locale afin de produire les marchandises destinées aux principaux marchés des pays centraux. Pour mieux comprendre l'évolution et la situation actuelle de cette industrie, le travail sur le terrain s'est déroulé en plusieurs endroits, surtout dans les deux usines de traitement de la noix de cajou situées dans le district de Manjacaze (province de Gaza). On a choisi une stratégie méthodologique basée sur une ethnographie éparpillée dans l'espace, au lieu de l'approche classique centrée sur l'étude d'un seul lieu et d'une communauté, apparemment isolés et autonomes.

Mots-clé: Mozambique; industrie du cajou; politiques de production 